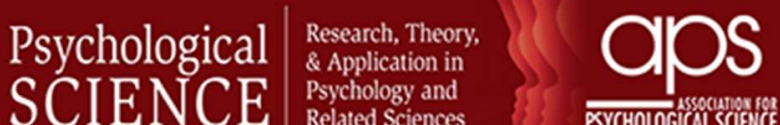

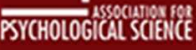

Fictional First Memories

\begin{tabular}{|r|l|}
\hline Journal: & Psychological Science \\
\hline Manuscript ID & PSCI-16-1434.R3 \\
\hline Manuscript Type: & Research Article \\
\hline Complete List of Authors: & $\begin{array}{l}\text { Akhtar, Shazia; City, University of London, Psychology } \\
\text { Justice, Lucy; Nottingham Trent University School of Social Sciences, } \\
\text { Psychology } \\
\text { Morrison, Catriona; University of Bradford, Psychology } \\
\text { Conway, Martin; City University, Psychology }\end{array}$ \\
\hline Keywords: & $\begin{array}{l}\text { Childhood Development, False Memory, Memory, first memories, age at } \\
\text { encoding, age at retrieval, childhood amnesia, fictional memories, narrative } \\
\text { memories., First Memories }\end{array}$ \\
\hline \multicolumn{2}{|c}{} \\
\hline
\end{tabular}


RUNNING HEAD: First Memories

\title{
Fictional First Memories
}

\author{
${ }^{1}$ Shazia Akhtar, ${ }^{2}$ Lucy V. Justice, ${ }^{3}$ Catriona M. Morrison, \& ${ }^{1}$ Martin A. Conway \\ ${ }^{1}$ Department of Psychology, City, University London \\ ${ }^{2}$ Department of Psychology, Nottingham Trent University \\ ${ }^{3}$ Department of Psychology, University of Bradford
}

Word Count (excluding Abstract and References): 3775

Corresponding author:

Professor Martin A. Conway, Department of Psychology, City, University of London

The Rhind Building

Northampton Square,

London, EC1V 0HB

Email: Martin.Conway.1@,city.ac.uk 


\begin{abstract}
$\underline{\text { Abstract }}$
In a large-scale survey 6641 respondents provided descriptions of their first memory, age-at-encoding (AaE), and completed various memory judgments and ratings. In good agreement with many other studies, where mean AaE of earliest memories is usually found to fall somewhere in the first half of the third year of life, the mean AaE here was 3.2 years. The established view is that the distribution around mean $\mathrm{AaE}$ is truncated with very few or no memories dating to the preverbal period, i.e. below about two years of age. However, we found that 2487 first memories (nearly $40 \%$ of the entire sample) dated to an AaE of two years and younger with 893 dating to one year and younger. We discuss how such improbable, fictional, first memories could have arisen and contrast them with more probable first memories, those with an $\mathrm{AaE}$ of three years and older.
\end{abstract}

Key terms: first memories, age at encoding, age at retrieval, childhood amnesia, fictional memories, narrative memories. 
In many studies of the recall of earliest memories the first memory is found to date to the 3rd year of life, typically about 3 years 4 months (Hayne, 2004; Kingo, Berntsen, \& Krøjgaard, 2013a; Pillemer \& White, 1989; Rubin, 2000; Wang, Conway, \& Hou, 2004). However, also in many studies, there are always a few respondents who date their earliest memory to 2 years of age and below (Hayne, 2004; Wells, Morrison \& Conway, 2013; see too Kingo, Berntsen, \& Krøjgaard, 2013b). Indeed, there is some evidence that distinctive family events, e.g. the birth of a sibling, etc., might lead to the formation and long-term retention of unusually early first memories (Eacott \& Crawley, 1998; Usher \& Neiseer, 1993, but see Gross, Jack, Davis, \& Hayne, 2013, and Loftus, 1993, for a critique of the validity of such 'memories'). Here we had the unique opportunity to sample a large group of adults across the age range and to examine first memories in groups not usually sampled, as previous studies typically have only used young adults.

Interestingly the study of memory development similarly dates the emergence of first memories to the age of about 3 to 4 years. Howe, Courage, and Edison (2003) in their review of the area concluded that the processes underlying the ability to form autobiographical memories are functional by the $3^{\text {rd }}$ year of life, but they also note that other factors, e.g. sociolinguistic development, may further lengthen the period during which full autobiographical memories form (see too Bauer 2007, 2015, and Howe, 2011, for recent reviews that reach similar conclusions). In one of the only experimental studies Simcock and Hayne, (2002) found that children exposed to an interesting and novel event below the age of 3 years showed signs of preverbal memory yet failed to translate the memory into language both 6 months and 1 year later. Results suggest that no enduring 
autobiographical memory of the target event was formed in the first place or, possibly, no memory that could be declaratively reported was formed. The obvious implication being that if children below the age of 2 to 3 years cannot form full autobiographical memories then it is not possible for adults to recall such memories from these ages.

Consistent with the findings from the study of the development of memory are the outcomes from studies of (young) adults recalling first memories. These variously date the emergence of first full autobiographical memories to fall somewhere between the ages of 3 to 5 years. Rubin (2000), in a meta-analysis of over 11,000 early memories recalled by adults found the emergence of memories to date to about 3.4 years of age, with virtually no memories falling below the age of 3. Moreover, of the 770 respondents who contributed memories to this review over $76 \%$ (590) were younger than 30 , meaning that the findings are limited to a comparatively young population (largely undergraduate university students). In contrast, Bruce, Dolan, and Phillips-Grant, (2000), found full first autobiographical memories to date to 5 to 6 years of age and term "memories" below this age "fragments" that were not recollectively experienced when recalled. But even with "fragments" very few dated to below the age of 3 years. The overwhelming evidence and theory is then that full earliest autobiographical memories do not emerge before about the age of about 24 to 36 months and, if anything, the onset of full autobiographical memories may not be until later than this.

In the present study we conducted the first large-scale web-based survey of first memories (rather than the more general category of early memories used in many previous studies, see Rubin, 2000). Thus, the key variable in the present 
study was respondents' estimates of their age when their first memory was formed: age at encoding $(\mathrm{AaE})^{1}$. Moreover, because this was a large-scale study we were able to sample across the full age range and draw on the general population. Uniquely, the survey was linked to a popular series of radio programs on memory produced and broadcast by the British Broadcasting Corporation (BBC) Radio 4 in the United Kingdom (2007). The programs can be listened to at http://www.bbc.co.uk/radio4/memory/listenagain/. The survey is no longer live but the questionnaire that was used is included in the Supplemental Materials.

\section{Method}

In the first program of the radio series the fourth author introduced the idea that the program would conduct a memory survey of various types of memories (earliest, self-defining, and flashbulb memories) and report the results of the survey in a later program. The audience were invited to log into a memory web site hosted by the BBC that contained various sources of information about memory and separate questionnaires for each of the three types of memories-to-be sampled. The questionnaires always began with an information page outlining key instructions regarding the nature of the to-be-sampled memory, an informed consent box to be checked, and minimal demographic data was collected. Respondents were also informed that after recalling their earliest memory they would be asked to answer some questions about the memory. For these questions they were instructed not to guess or infer answers but to only answer if they actually remembered the answer.

\footnotetext{
1 Other rating measures of vividness, emotional intensity and memory perspective were also collected but as these were secondary measures and not found to be systematically related to AaE. Consequently, they are reported in the Supplemental Materials.
} 
Respondents then moved to the next page of the questionnaire proper. They were instructed to recall and then type a title and description (in the box provided) of their very earliest memory. The title was to be only a few words in length but of sufficient specificity that if they read it again it would remind them of the memory they had recalled. The memory description was to be about a paragraph or so in length. The memory itself had to be one that they were certain they remembered. It should not be based on, for example a family photograph, family story, or any source other than direct experience. The memory had to be for a specific one-off event that lasted no longer than minutes/hours. It was specifically emphasised that the memory should not be of a routine or repeated event. After entering the title and memory description respondents were then asked to enter, in years, the age they believed they were in the memory. Following this, the respondents answered a series of questions regarding the recollective qualities of the memory (see Supplemental Materials for details). Results

Figure 1. Percentage of respondents across age groups 


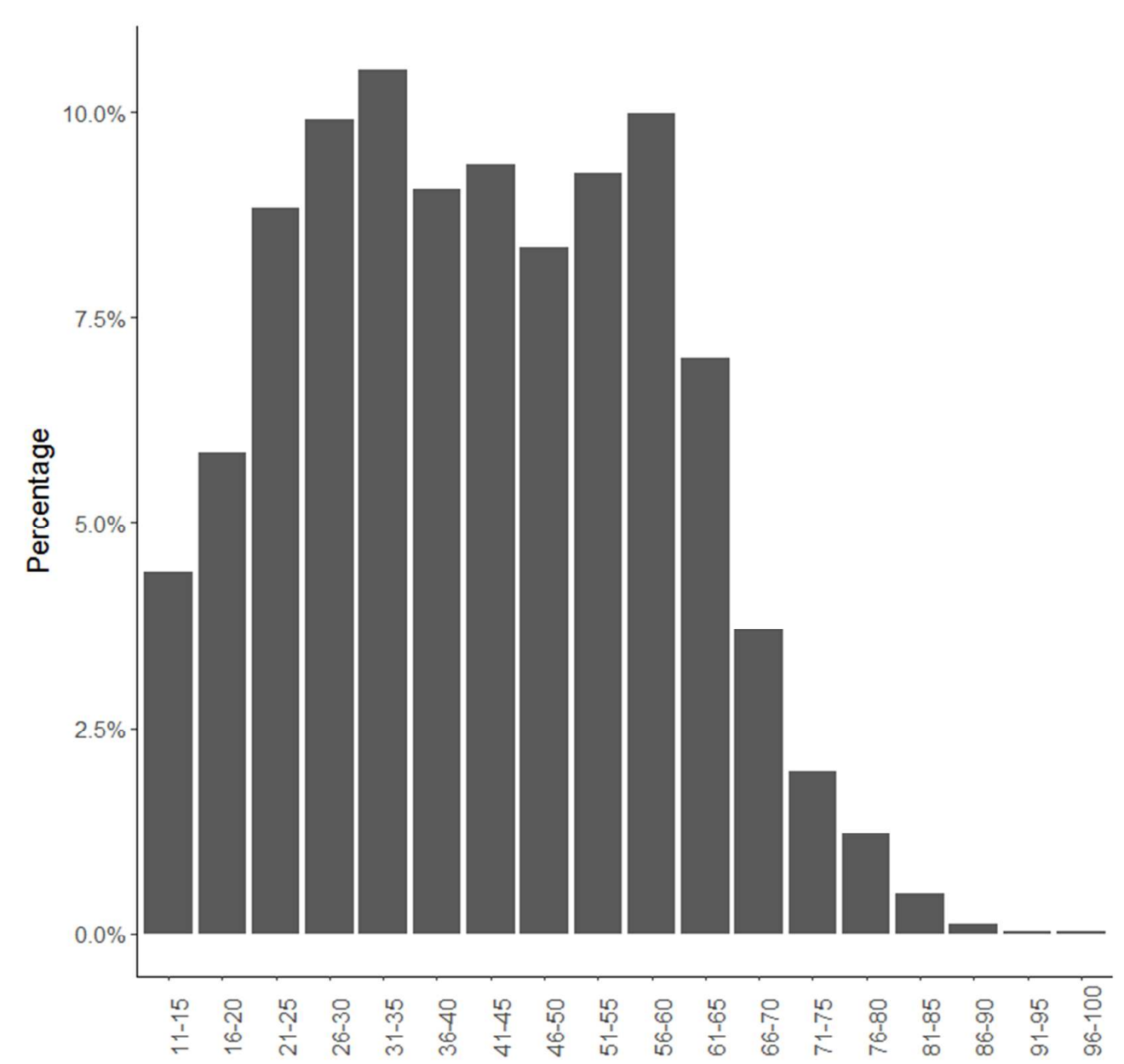

Participant Age Group

There were 6671 respondents who completed the survey. Inspection of the memory descriptions led to 166 responses being judged unusable because the memory description was vague and lacked (any) specificity or because it was explicitly stated to be based on a family story or photograph. Further, 39 memories with reported age at encoding over 15 years were not used due to their unusually late age at encoding and finally respondent age groups 0-5 $(n=4)$ and 6-10 $(n=21)$ were removed due to very low age of the respondent (which were likely typographical errors). Thus, a total of 6441 memories were used and of these 4115 were from female respondents $(63.9 \%)$, with a mean age of $42.12(95 \% \mathrm{CI}=41.61$ $-42.63)$ and 2326 were from male respondents (36.1\%) with a mean age of 41.56 
$(95 \% \mathrm{CI}=40.89-42.22)$. Eighty-two percent $(5550)$ of respondents were UK

nationals, with the remaining $13.8 \%$ (891) residing in other parts of the world.

Figure 1 shows the distributions of memories across age groups of respondents, and shows clearly that memories were sampled across the lifespan.

Figure 2. Frequency of Age at Encoding (AaE) grouped by memory type

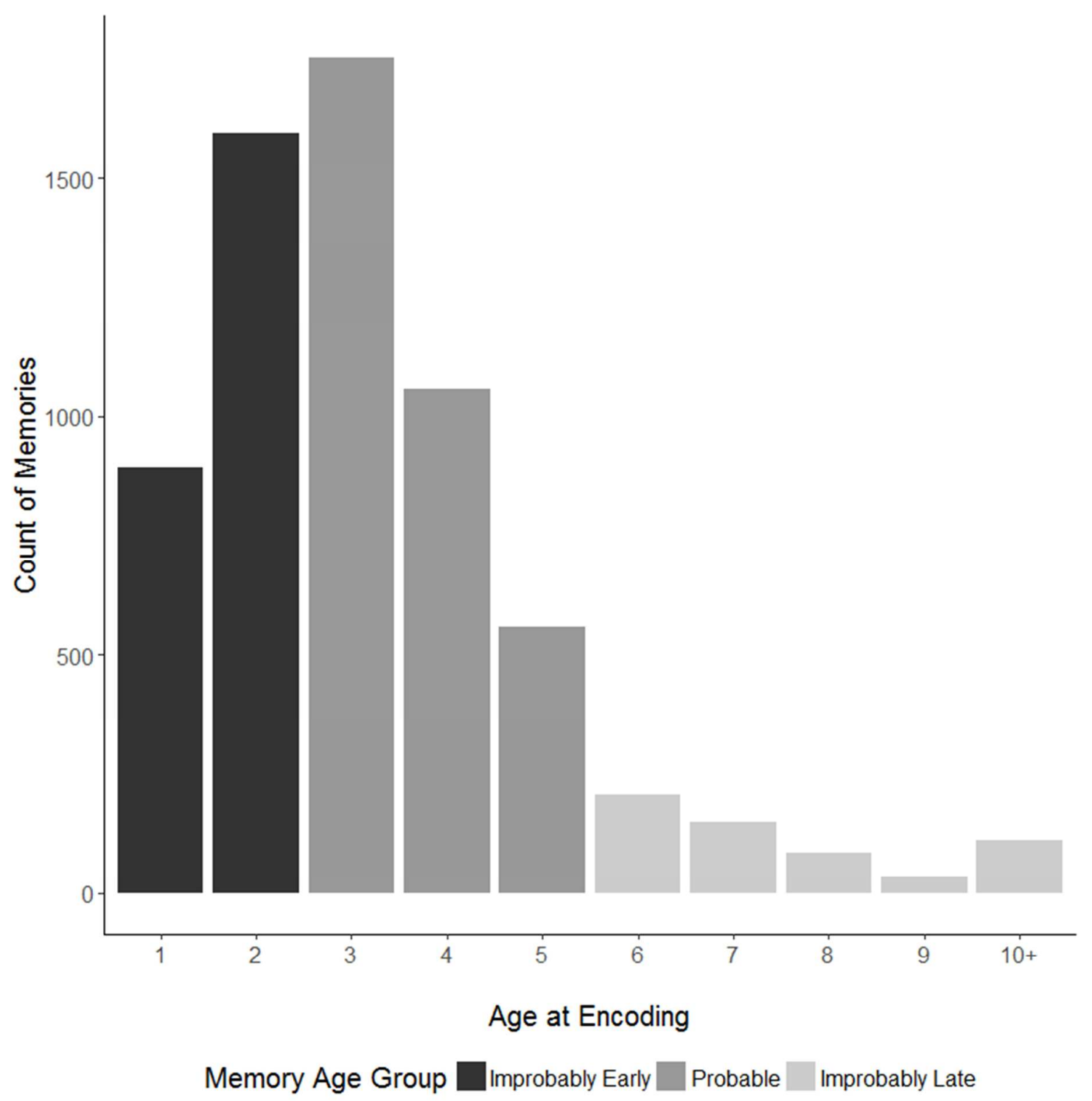


Figure 2 shows the frequency of AaE across the sample ${ }^{2}$. What is immediately evident in Figure 2 is that there were a large number of unexpectedly early memories with $38.6 \%$ (2487) of the sample having what we term improbably early memories dating to two years and younger $(\mathrm{M}=1.64,95 \% \mathrm{CI}=1.62-$ 1.66), 52.3\%, (3371) of respondents reported what we term probable memories, falling between $\mathrm{AaE}$ of two and five years $(\mathrm{M}=3.65,95 \% \mathrm{CI}=3.62-3.67)$ and the remaining $9.1 \%$ (583) of respondents reported an AaE of six plus years $(\mathrm{M}=$ $7.72,95 \% \mathrm{CI}=7.55-7.90)$, which we term improbably late memories.

Thus, the AaE of most memories fell in the predicted range, two years to five years old, however, the second largest group of memories had AaEs that were unexpectedly early falling in the period of two years and less and these were greater in number than improbably late memories dating to $6+$ years and older. Despite this unexpected distribution, the overall mean AaE of the whole sample was $3.24(95 \% \mathrm{CI}=3.19-3.29)$ years comparing favourably with previous findings of the mean age of the earliest memory that place it in the first half of the third year of life.

Next, we investigated if $\mathrm{AaE}$ varied as a function of respondent age. In particular, we wanted to investigate whether the AaE reported in most earliest memory studies is somewhat skewed due to the sampling of younger adults. The sample was therefore split into two new groups: a younger group comprised of

2 The full data set can be accessed at city.figshare.com with the DOI of: https://doi.org/10.25383/city.6115676 
respondents within the $11-15,16-20$ and $21-25$ age groups $(n=1228)$, similar to the majority of participant's sampled in Rubin's (2000 study) and an older group comprised of all remaining respondents $(\mathrm{n}=5213)$. The mean AaE was $3.56(95 \%$ $\mathrm{CI}=3.44-3.68)$ for the younger group and $3.16(95 \% \mathrm{CI}=3.11-3.22)$ for the older group. These means were reliably different $(\mathrm{t}(1695)=6.02, \mathrm{p}<.001, d=.19$ $(95 \% \mathrm{CI}=.13-.25))$, showing that the older group had reliably earlier first memories than the younger group. The mean age of the younger group's earliest memories was then more consistent with previous studies using young adults, although we note that in the present study even some of this group had memories dating to 2 years and below ${ }^{3}$.

\section{Memory Content}

It is hypothesised that early memories are "fragments" of memories (Bruce, et al., 2000), lacking rich and detailed descriptions. This was tested in the present study by, firstly, assessing the word count of the memory descriptions as a function of memory group. A Poisson regression with planned comparisons (early vs probable and early vs late) found no reliable difference in word count between improbably early memories $(\mathrm{M}=69.20,95 \% \mathrm{CI}=67.02-71.38)$ and probable memories $(\mathrm{M}=68.82,95 \% \mathrm{CI}=66.87-70.76 ; p=.14, b=.007,95 \% \mathrm{CI}=-.002$ - .017) but improbably early memories had a reliably shorter word count than improbably late memories $(\mathrm{M}=70.33,95 \% \mathrm{CI}=65.78-74.88 ; p<0.001, b=$ $.025,95 \% \mathrm{CI}=.011-.039)$. Although reliably different, memories across all three categories had negligible differences in word count ( \pm 1 words), thus, contrary to

\footnotetext{
${ }^{3}$ As far as judgments of recollective qualities were concerned all memories, regardles of group were of moderate vividness and were rated as being recalled moderately often. Interestingly improbably early memories were more strongly associated with an observer than field perspective, see the Supplemental Materials for full analyses.
} 
the suggestion that early memories are "fragments", the present findings show that they are similar in length to both probable and improbably late first memories.

Secondly, the corpus of memory descriptions was then further analysed using the Alceste Software for statistical analysis of textual data. This software bridges quantitative and qualitative methods, analysing natural language using multivariate statistical methods to identify groups of words i.e. phrases and sentences that reliably cluster together across different contexts. The resulting output provides categories of dominant themes in the corpus that are required to be named by the analyst. ${ }^{4}$ Separate analyses were performed on the descriptions of improbably early, probable, and improbably late memories, yielding a linguistic profile for each memory group (Table 1).

Table 1. Percentage of memories within each semantic category across memory types

\begin{tabular}{|c|c|c|}
\hline Memory Type & Category ( $\%$ of memories) & Example \\
\hline \multirow[t]{3}{*}{ Improbably Early } & Pram (baby carriage) $(52 \%)$ & I was lying in my pram.... \\
\hline & Family relationships $(30 \%)$ & My parents were going on holiday and me and my elder sister. \\
\hline & Feeling sad (18\%) & I remember feeling very sad, my mum..... \\
\hline \multirow[t]{7}{*}{ Probable } & Toy $(20 \%)$ & ...my uncle had bought me a loopy loo doll. It was almost as.. \\
\hline & Birth of a sibling $(16 \%)$ & ...the arrival of my baby brother. When has was born and my... \\
\hline & Home $(16 \%)$ & ...the front door opened directly into the kitchen which had... \\
\hline & School $(15 \%)$ & ...my first day at primary school, there was another little girl.. \\
\hline & Crying (11\%) & ...I remember crying hysterically...I would not be comforted.. \\
\hline & Holidays $(11 \%)$ & ...we travelled to a holiday camp in Sussex on the Small Hythe.. \\
\hline & Dreams $(11 \%)$ & ...being potty trained in my dream... \\
\hline \multirow[t]{3}{*}{ Improbably Late } & Home $(59 \%)$ & In the winter of 1940 we lived in south London... \\
\hline & Activities $(26 \%)$ & ...playing football with my friends... \\
\hline & School $(15 \%)$ & I attended the local school. The school remained open... \\
\hline
\end{tabular}

${ }^{4}$ Full details can be found at: http://www.image-zafar.com/Logicieluk.html 
In Table 1 it can be seen that $100 \%$ of descriptions of improbably early memories fit into one of three categories, the dominant category being memory descriptions in which a pram (baby carriage) featured across various contexts. We also note that the category 'birth of sibling', that has previously been identified as an event likely to give rise to very early first memories (Eacott \& Crawley, 1998; Usher \& Neiseer, 1993,), did not feature in any of the improbably early memories analysed in the study corpus. In contrast, $100 \%$ of descriptions of probable memories were accounted for by seven categories, all of which clustered around words and phrases referring to aspects of childhood and many descriptions featured toys in a wide variety of contexts (see Table 1). Finally, $100 \%$ of descriptions of improbably late memories decomposed into three categories with the dominant category featuring descriptions that mentioned home in a wide variety of contexts. In summary, the linguistic analysis of the memory descriptions found them to be age appropriate; descriptions of improbably early memories referred to events and activities from infancy, i.e. being pushed in a pram/baby carriage, probable memories referred to events and activities from early childhood, e.g. playing with toys, and improbably late memories often referred to events in the home, e.g. family gatherings of various sorts, (examples of memories for each category are included in the Supplemental Materials).

\section{Discussion}

The present findings pose a major conundrum: the child and (young) adult research, as reviewed earlier, all conclude that earliest memories cannot exist below about the age of two years and that there would be comparatively few memories below the age of three years. Yet the main finding of the present survey of earliest memories, the largest such survey ever conducted, is that $2487(38.6 \%$ 
of the entire sample) of the earliest memories dated to when respondents were two years of age or younger, with, astonishingly, 893 (13.9\%) dating to one year or younger. These are what we have termed improbable first memories and the question is how best to explain them? Below we evaluate three possible explanations: misdating, nature of the respondents, and the narrative and fictional nature of the 'life story' (Habermas \& Bluck, 2000; Kober, Schmiedek, \& Habermas, 2015).

\section{The Misdating Explanation}

Dating of all autobiographical memories, including childhood memories, is predominantly inferential and specific calendar and age dates are rarely retained in long-term memory (Thompson, Skowronski, \& Larsen, 1996). Thus, it is possible that some of the dates given for first memories in the present study are incorrect estimates, indeed it would be remarkable were they not. We assume, however, that such misdating is random rather than systematic and therefore represents noise in the AaE measure. Nonetheless, a plausible misdating account of the present findings might propose that, for unknown reasons, almost $40 \%$ of the sample systematically backward-telescoped their estimates of the AaE of their first memories (see Wang \& Peterson, 2014, for evidence of forward telescoping in estimates of earliest memories).

If the misdating account were correct then it would be expected that the improbable early memories would be about events similar to those that were dated to three years and older. But this was not the case and our content analysis found that improbable first memories were of events that related to infancy whereas memories dating to three years and older (probable first memories) were of events related to childhood (see Table 1). These findings of differences in the content of 
improbably early and probable first memories effectively rule out the systematic misdating explanation.

The Respondents: Self-Selection

The present sample of respondents differed from most previous studies in that they consisted of individuals from across the lifespan. Given that they freely responded to the request to complete a web-based memory survey they were selfselected. Self-selection is common in most psychological research, after all even the student participating for course credit is self-selected. Random selection is typically not practically possible, particularly given resource constraints. Nevertheless, a very large sample, even if self-selected, has the advantage of very high power. In the present study power approached 1 for all effect sizes, far higher than that in most psychology research and indeed in most social science research.

Yet, the possibility remains that there is some unique aspect of this sample. One possibility is that this group have thought about, i.e. rehearsed, their past more than other groups and in the course of so doing have, perhaps implicitly or nonconsciously, generated cues that allowed them to access far earlier memories than those accessed in previous studies. The present findings suggest that this may occur more frequently in older than younger adults. A problem for this explanation, however, is that there were no differences in rated rehearsal between the older and younger groups, both of who indicated equal moderate levels of rehearsal (see Supplemental Materials). Instead, it may be that middle-aged adults have a more developed life-story than younger adults - one that incorporates and constructs knowledge from, or about, infancy (their own, possibly others, possibly infancy in general) into the form of memories or what we here term fictional memories. 


\section{The Life-Story and Fictional Memories}

If the improbably early memories, memories that research tells us cannot be formed at such young ages, are largely of imagined rather than experienced events how do these fictional memories arise? Note that we use the term "fictional memories" here rather than "false memories" or "illusory memories" for a number of reasons. One is that the term "false memories" has a pejorative aspect to it false memories are negative and the term "illusory memories" suggests some sort of memory error. Although we note that more recent work has found positive aspects to false memories (see Howe, 2011; Howe, Wilkinson, Garner, \& Ball, 2016; Schacter, Guerin, \& St. Jacques, 2011). Moreover there may be adaptive consequences of fictional memories more generally. For example, in adulthood preserving a positive and consistent self-narrative helps a person maintain a positive self-image that can foster positive social interactions with others, ones that arguably enhance the rememberer's quality of life (see Ross \& Wilson, 2000, 2003). Fictional memories are then part of the life-story and may play a central, and positive, role in defining periods of life or lifetime periods (Conway, 2005; Conway \& Pleydell-Pearce, 2000). It is particularly noteworthy that all the memories we sampled, improbably early, probable, improbably late, included ageappropriate events and viewed overall they give a picture of a life story with successive early periods each with a distinctive content.

Thus, in our analysis of the content of the descriptions of memories from the different AaEs, see Table 1, we found that accounts dating to two years and earlier contained details relating to infancy. Under the three broad categories of pram (baby carriage), family relationships and feeling sad, these were details such as "an image of my pram", "being in my cot", "in my push chair", "having my nappy 
changed", and even more implausibly "the first time I walked", "wanting to tell my mother something before I could talk", "the first word I spoke", and so on. On the basis of these descriptions we suggest that what people often have in mind when "recalling" these improbably early memories is an image (often visual) of an object or action possibly dating to very early childhood. This might be based on experience or derived from a photograph or a description (the rememberer may not be aware of the source of their image/s). Other sources of details for improbably early memories may derive from family stories/history, e.g. the first word you spoke was "X", all you ever wanted to do when you were little was walk, etc. These facts of infancy, possibly along with some visual fragments, form the basis of remembering infancy: their source is believed to be, or even experienced as being from these very early ages and, accordingly, dated to those times. Thus, we suggest that what a rememberer has in mind when recalling fictional improbably early memories is an episodic-memory-like mental representation consisting of remembered fragments of early experience and some facts or knowledge about their own infancy/childhood. Additionally, further details may be non-consciously inferred or added, e.g. that one was wearing nappy when standing in the cot. Such episodic-memory-like mental representations come, over time, to be recollectively experienced (Gardener \& Richardson-Klavehn, 2000) when they come to mind and so for the individual they quite simply are "memories", memories that their content indicates date to a particular time: infancy.

We suggest that improbably early first memories fall in a larger class of fictional memories. Indeed, in the constructive view of memory all memories contain some degree of fiction. For example, all memories are time-compressed and, therefore, do not literally represent the experience from which they derive. 
Similarly, all memories contain details that are both consciously and nonconsciously inferred. For example, Wells, et al., (2013) found that clothes in childhood memories were poorly recalled. Nonetheless, respondents in that study recalled that they had been clothed and the same applies to many other types of details, e.g. weather, time of day, conversations, etc., that are also (nonconsciously) inferred rather than remembered. Memories, then, are part of a narrative of a person's life and the way in which they correspond to experience and cohere with other memories is complex and dynamic.

Note that, we use the term narrative as it used by Goldie (2012) in his account of narrative thinking which is an internal mental representation rather than a publically presented account. In this conception the personal value and significance of a fictional memory resides in how coherent it is with other parts of autobiographical memory rather than with how well it corresponds to a previously experienced reality (see Conway, 2005, and Conway, Loveday, \& Scott, 2016, for discussion of coherence and correspondence in autobiographical memory). Perhaps what is important when it comes to questions of accuracy of a memory, from any age, is the extent of fictionalisation of details. In the present study the data indicate that fictional very early memories are more common in middle-aged and older adults and about 4 in 10 of this group have fictional memories for infancy. To a lesser degree they are also present in some younger people. Perhaps, the life narrative/story, mainly for the middle-aged, needs to extend, (for reasons that are not yet understood, but possibly to do with coherence and completeness of the life narrative), to the very earliest years of life and hence the emergence of improbably early fictional first memories. 


\section{$\underline{\text { References }}$}

Bartholomew, K., \& Shaver, P. R. (1998). Methods of assessing adult attachment: Do they converge? In J. A. Simpson \& W. S. Rholes (Eds.), Attachment Theory and Close Relationships (pp. 25-45). New York: Guilford.

Bauer, P. J. (2007). Remembering the times of our lives: Memory in infancy and beyond. Mahwah, NJ: Lawrence Erlbaum Associates Inc.

Bauer, P.J. (2015). A Complementary Processes Account of the Development of Childhood Amnesia and a Personal Past. Psychological Review, Vol. 122, No. 2, 204-231.

Benzécri, J.P. (1981) Pratique de l'Analyse des Données: linguistique et lexicologie. Paris: Dunod.

Bruce, D., Dolan, A., \& Phillips-Grant, K. (2000). On the transition from childhood amnesia to the recall of personal memories. Psychological Science, 11, 360-364. doi:10.1111/1467-9280.00271

Conway, M.A. (2005). Memory and the self. Journal of Memory and Language, 53(4), 594-628.

Conway, M.A. (2009). Episodic Memories. Neuropsychologia, 47, 23052313.

Conway, M.A., Loveday, C., \& Cole, S.N. (2016). The rememberingimagining system. Memory Studies, 9(3), 256-265.

Conway, M. A., \& Pleydell-Pearce, C. W. (2000). The construction of autobiographical memories in the self memory system. Psychological Review, 107, 261-288. 
Christensen, R. H. B. (2015). ordinal - Regression Models for Ordinal Data. R package version 2015.6-28.

Eacott, M. J., \& Crawley, R. A. (1998). The offset of childhood amnesia:

Memory for events that occurred before age 3. Journal of Experimental Psychology: General, 127, 22-33.

Gardiner, J.M., \& Richardson-Klavehn, A. (2000). Remembering and knowing. In E. Tulving \& F.I.M. Craik (Eds.), Handbook of memory (pp. 229244). Oxford: Oxford University Press.

Garry, M., Manning, C.G., Loftus, E.F., \& Sherman, S.J. (1996).

Imagination Inflation: Imagining a Childhood Event Inflates Confidence that it Occurred. Psychonomic Bulletin \& Review 1996, 3 (2), 208-214.

Goldie, P. (2012). The mess inside. Narrative, emotion \& the mind. Oxford: Oxford University Press.

Gross, J., Jack, F., Davis, N., \& Hayne, H. (2013). Do children recall the birth of a younger sibling? Implications for the study of childhood amnesia. Memory, 21(3), 336-346.

Habermas, T., \& Bluck, S. (2000). Getting a life: The emergence of the life story in adolescence. Psychological Bulletin, 126, 748-769.

Hayne, H. (2004). Infant memory development: Implications for childhood amnesia. Developmental Review, 24, 33-73.

Howe, M. L. (2011) The Nature of Early Memory: An Adaptive Theory of the Genesis and Development of Memory. Oxford: Oxford University Press.

Howe, M. L. (2011). The adaptive nature of memory and its illusions. Current Directions in Psychological Science, 20, 312-315. 
Howe, M. L., Wilkinson, S., Garner, S. R., \& Ball, L. J. (2016). On the adaptive function of children's and adults' false memories. Memory, 24, 10621077.

Howe, M. L., \& Courage, M. L. (1997). The emergence and early development of autobiographical memory. Psychological Review, 104, 499- 523. http://dx.doi.org/10.1037/0033-295X.104.3.499

Howe, M.L., Courage, M.L., \& Edison, S.C. (2003). When autobiographical memory begins. Developmental Review, 23, 471-494.

Justice, L. V., Morrison, C. M., \& Conway, M. A. (2016). Intentionally fabricated autobiographical memories. The Quarterly Journal of Experimental Psychology, 1-7.

Justice, L. V., Morrison, C. M., \& Conway, M. A. (2013). True and intentionally fabricated memories. Quarterly Journal of Experimental Psychology. 66, 6, p. 1196-1203.

Kingo, O. S., Berntsen, D., \& Krøjgaard, P. (2013a). Adults’ earliest memories as a function of age, gender, and education in a large stratified sample. Psychology and Aging, 28, 646-653.

Kingo, O. S., Bohn, A., \& Krøjgaard, P. (2013b). Warm-up questions on early childhood memories affect the reported age of earliest memories in late adolescence. Memory, 21, 280-284.

Köber, C., Schmiedek, F., \& Habermas, T. (2015). Characterizing lifespan development of three aspects of coherence in life narratives: A cohort-sequential study. Developmental Psychology, 51, 260-275. 
Loftus, E.L. (1993). Desperately seeking memories of the first few years of childhood: The reality of early memories. Journal of Experimental Psychology: General, 122(2), 274-277.

Pillemer, D. B., \& White, S. H. (1989). Childhood events recalled by children and adults. In H. W. Reese (Ed.), Advances in child development and behavior (Vol. 21) (pp. 297 340). New York: Academic Press.

R Core Team (2016). R: A language and environment for statistical computing. R Foundation for Statistical Computing. Vienna, Austria.

Ross, M., \& Wilson, A. E. (2000). Constructing and appraising past selves. In D. L. Schacter \& E. Scarry (Eds.), Memory, brain, and belief (pp. 231-259). Cambridge, MA: Harvard University Press.

Ross, M., \& Wilson, A. E. (2003). Autobiographical memory and conceptions of the self: Getting better all the time. Current Directions in Psychological Science, 12, 66-69.

Rovee-Collier, C. (1997). Dissociations in infant memory: Rethinking the development of implicit and explicit memory. Psychological Review, 104, 467498.

Rubin, D. C. (2000). The distribution of early childhood memories. Memory, 8(4), 265269.

Schacter, D. L., Guerin, S. A., \& St. Jacques, P. L. (2011). Memory distortion: An adaptive perspective. Trends in Cognitive Sciences, 15, 467-474.

Simcock, G., \& Hayne, H. (2002). Breaking the barrier? Children fail to translate their preverbal memories into language. Psychological Science, 13, 225231. 
Thompson, C.P., Skowronski, J.J., \& Larsen, S.F. (1979). Autobiographical Memory: Remembering What and Remembering When. Mahwah, N.J.: Lawrence Erlbaum Associates, Publishers.

Tulving, E. (1983). Elements of episodic memory. New York: Oxford University Press.

Tulving, E. (2002). Episodic memory: From mind to brain. Annual Review of Psychology, 53, 1-25.

Usher, J. A., \& Neisser, U. (1993). Childhood amnesia and the beginnings of memory for early life events. Journal of Experimental Psychology: General, 122, $155-165$.

Wang, Q., Conway, M. A., \& Hou, Y. (2004). Infantile amnesia: A crosscultural investigation. Cognitive Sciences, 1(1), 123135.

Wang, Q., \& Peterson, C. (2014). Your Earliest Memory May Be Earlier Than You Think: Prospective Studies of Children's Dating of Earliest Childhood Memories. Developmental Psychology, 50,(6), 1680-1686.

Wells, C., Morrison, C. M., \& Conway, M. A. (2014). Adult recollections of childhood memories: What details can be recalled?. The Quarterly Journal of Experimental Psychology, 67(7), 1249-1261. 


\begin{abstract}
Authorship Section
The first author worked as the fourth author's post-doctoral research assistant during this research and preparation of the paper. Although both made different contributions both agree that their contributions were equal. The second author assisted with the statistical analyses and the third with the initial preparation of the data. We thank John Partington of the BBC who created the original web-site. The data set is archived at city.figshare.com
\end{abstract}




\author{
Authors' Note \\ We thank the BBC for supporting this work and Dr. Katryn Hohl and Professor \\ Mark L. Howe for comments on an earlier version.
}

